\title{
PENGARUH MODEL PEMBELAJARAN KOOPERATIF TIPE TEAM ASSISTED INDIVIDUALIZATION TERHADAP HASIL BELAJAR MATEMATIKA SISWA
}

\author{
Gina Ayu", Yesi Gusmania \\ ${ }^{1}$ Program Studi Pendidikan Matematika, Fakultas Keguruan dan Ilmu Pendidikan \\ Universitas Riau Kepulauan, Batam, Kepulauan Riau, Indonesia \\ e-mail: *Ginaayu0026@gmail.com
}

\begin{abstract}
Abstrak. Penelitian ini bertujuan untuk mengetahui (1) Pengaruh model pembelajaran Tipe Team Assisted Individualization terhadap hasil belajar matematika, (2) Pengaruh model pembelajaran Konvensional terhadap hasil belajar matematika, (3) Perbedaan pengaruh model pembelajaran Tipe Team Assisted Individualization dengan model pembelajaran Konvensional terhadap hasil belajar matematika. Jenis penelitian ini adalah Quasi Eksperimental dengan desain Non-equivalent PosttestOnly Control Group Design. Populasi penelitian adalah seluruh Siswa Kelas XI SMK Widya 2 Batam tahun pelajaran 2017/2018 dengan jumlah 34 siswa. Teknik pengampilan sampel dilakukan dengan teknik Sampling Jenuh. Instrumen yang di gunakan berupa esai sebanyak 8 soal. Analisis yang digunakan uji validitas dan reliabilitasnya. Analisis data yang digunakan adalah one sample t test dan independen sample test. Hasil penelitian menunjukan: (1) Terdapat pengaruh model pembelajaran Team Assisted Individualization terhadap hasil belajar, hal ini terlihat dari $\left(t_{\text {hitung }}>t_{\text {tabel }}\right)$ $(3,096>2,093)$ (2) Tidak terdapat pengaruh model pembelajaran Konvensional terhadap hasil belajar, hal ini terlihat dari $\left(t_{\text {hitung }}<t_{\text {tabel }}\right)(-1,844<2,160)$, (3) Terdapat perbedaan pengaruh antara model pembelajaran kooperatif tipe Team Assisted Individualzation denganmodel pembelajaran konvensionalterhadap hasil belajar Matematika $\left(t_{\text {hitung }}=3,385>t_{\text {tabel }}=2,037\right)$
\end{abstract}

Kata Kunci :Team Assisted Individualization, Hasil Belajar.

Abstract. This research intent to know: (1) influence of learning model of Team Assisted Individualization to mathematics learning result, (2) the influence of conventional learning model on mathrmatics learning autcomes, (3) differences in Team Assisted Individualization learning model with conventional learning model on mathematics learning autcomes. The type of this research was quasi experimental research with Non-equivalent Posttest-Only Control Group Design. The population in this research is all of students at eleventh grade students of SMK Widya 2 Batam in 2018/2019 academic year with two classes that total 34. The techniqeue of collecting sample used sampling jenuh. The data obtained used instrument test has tested validity and reliability. The data analysis used one simple $t$ test and independent samles test. The finding results showed: (1) there are influence of Team Assisted Individualization learning model on learning outcomes, this is seen $\left(t_{\text {hitung }}>t_{\text {tabel }}\right)$ $(3,096>2,093)$ (2) there is no conventional learning model on the learning outcomes, this is seen $\left(t_{\text {hitung }}<t_{\text {tabel }}\right)(-1,844<2,160)$ (3) there are differences in the influence of Team Assisted Individualization learning model with the conventional learning midel on mathematics learning outcomes ( $\left.t_{\text {hitung }}=3,385>t_{\text {tabel }}=2,037\right)$

Kata Kunci :Team Assisted Individualization, Learning Outcomes.

\section{Pendahuluan}

Pendidikan merupakan suatu proses perubahan sikap atau perilaku seseorang atau individu kelompok dalam upaya mendewasakan manusia melalui kegiatan pembelajaran dan pelatihan. Menurut Undang-Undang No.20 Tahun 2003 pasal 1 ayat 1 "pendidikan adalah usaha dasar dan terencana untuk mewujudkan suasana belajar dan proses pembelajaran agar siswa secara aktif mengembangkan potensi dirinya untuk memiliki kekuatan spiritual keagamaan, pengendalian diri, kepribadian, kecerdasan, akhlak mulia, serta keterampilan 
yang diperlukan dirinya, masyarakat, bangsa, dan Negara". Dalam pengertian pendidikan di atas, untuk melatih kecerdasan dan keterampilan siswa dapat dilakukan dengan cara mendalami dan memahami konsep-konsep matematika

Berdasarkan observasi yang dilakukan pada bulan januari 2018 cara mengajar guru yang terlihat yaitu guru mengajar dengan metode konvensional (ceramah) sehingga siswa menjadi bosan, mengantuk, pasif dan hanya mencatat pelajaran saja. Model-model yang digunakan guru dalam pembelajaran dikelas kurang bervariasi, sehingga cara mengajar guru tidak mampu menarik perhatian siswa dalam kegiatan belajar mengajar. Berdasarkan hasil wawancara dengan guru matematika bahwa kegiatan belajar mengajar siswa cenderung bersikap pasif seperti siswa malu untuk bertanya mengenai pelajaran yang belum dipahami.Selain itu, banyak siswa yang merasa kesulitan menyelesaikan soal yang berkaitan dengan materi yang diajarkan dan tidak berpartisipasi untuk mengeluarkan pendapat dalam kegiatan diskusi kelas, dan saat guru memberikan pertanyaan kepada siswa hanya beberapa orang yang bisa menjawabnya.

Hasil wawancara dengan siswa Kelas XI didapatkan juga informasi bahwa pada umumnya siswa mengatakan matematika mata pelajaran yang sulit karena harus menghafal rumus dan kurang memahami berbagai konsep, materi yang diberikan oleh guru dan hanya terfokus pada apa yang disampaikan guru di depan dan tidak benar-benar memahami apa maksud materi tersebut, dan malu untuk bertanya kepada guru, mereka lebih suka bertanya kepada teman. Permasalahan-permasalahan di atas berdampak pada rendahnya hasil belajar. Hal ini dapat dilihat dari nilai rata-rata UTS matematika kelas XI SMK Widya 2 Batam belum mencapai Kriteria Ketuntasan Minimal (KKM) yang ditetapkan yaitu 70, terlihat pada Tabel 1 di bawah ini.

Tabel 1. Data Nilai rata-rata UTS Mata Pelajaran Matematika Kelas XI SMK WIDYA 2 Batam Tahun Pelajaran 2017/2018

\begin{tabular}{clccc}
\hline No & \multicolumn{1}{c}{ Kelas } & Jumlah Siswa & Rata-rata & KKM \\
\hline 1 & XI Teknik & 20 & 42,08 & 70 \\
2 & XIGabungan & 14 & 54,16 & 70 \\
\hline
\end{tabular}

Sumber : Guru Matematika SMK WIDYA 2 Batam

Berdasarkan Tabel 1 di atas terlihat bahwa hasil belajar matematika siswa masih tergolong rendah yaitu di bawah rata-rata dari nilai yang telah di tetapkan oleh sekolah yaitu 70. Walaupun matematika telah dipelajari dari jenjang dasar, tetapi tidak bisa dipungkiri bahwa sampai saat ini banyak siswa yang menganggap bahwa matematika pelajaran yang paling tidak disukai.

Salah satu cara yang dapat dilakukan guru untuk meningkatkan hasil belajar siswa adalah dengan cara menerapkan model pembelajaran Team Assisted Individualization (TAI). Model pembelajaran kooperatif tipe TAI merupakan model pembelajaran yang membentuk kelompok kecil yang heterogen dengan latar belakang cara berfikir yang berbeda untuk saling membantu terhadap siswa lain yang membutuhkan bantuan (Shoimin, 2014). TAI juga merupakan proses pembelajaran dimana siswa yang lemah terbantu oleh siswa berkemampuan tinggi dalam menyelesaikan masalahnya, serta melibatkan siswa untuk aktif 
dalam proses belajar. Mengganti bentuk persaingan dengan saling bekerja sama, bertanggung jawab dan saling peduli dalam kelompok.

Dalam pembelajaran kooperatif dikenal dengan pembelajaran berkelompok. Pembelajaran kooperatif lebih dari sekedar belajar kelompok atau kerja kelompok karena dalam belajar kooperatif ada struktur dorongan atau tugas yang bersifat kooperatif sehingga memungkinkan terjadinya interaksi secara terbuka dan bersifat kreatif diantara anggota kelompok. Hubungan bekerja seperti itu memungkinkan timbulnya persepsi yang positif tentang apa yang dapat dilakukan oleh siswa untuk mencapai keberhasilan belajar berdasarkan kemampuan diri secara individu dan sumbangan dari anggota kelompok lain secara belajar bersama dalam kelompok.

Menurut Suyitno (Shoimin, 2014) Team Assisted Individualzation (TAI) memiliki dasar pemikiran yaitu untuk mengadaptasikan pembelajaran terhadap perbedaan individual berkaitan dengan kemampuan maupun pencapaian prestasi siswa.Metode ini termaksud dalam pembelajaran kooperatif dalam model pembelajaran TAI, siswa ditempatkan dalam kelompok-kelompok kecil (4 sampai 5 siswa) yang heterogen dan selanjutnya diikuti dengan pemberian bantuan secara individual bagi siswa yang memerlukan. Dengan pembelajaran kelompok, diharapkan para siswa dapat meningkatkan pikiran kritis, kreatif, dan menumbuhkan rasa sosial yang tinggi.

Langkah-langkah Model Pembelajaran Team Assisted Individualzation yang akan digunakan peneliti saat melakukan Penelitian di sekolah Menurut Slavin (Istarani \& Ridwan, 2014) yaitu:

1. Guru memberikan penjelasan umum tentang materi yang akan dibahas hari ini, yaitu menentukan $n$ suku pertama dan rumus suku ke- $n$ suatu barisan aritmatika

2. Pembentukan kelompok

Kelompok yang dibentuk beranggotakan 4-5 siswa dan bersifat heterogen

3. Pemberian bahan ajar

Pemberian materi yang akan diajarkan dalam bentuk Lembar Kerja Siswa (LKS) yang dibuat oleh guru.

4. Belajar dalam kelompok

Belajar dalam kelompok dilakukan untuk mendiskusikan materi yang ada dalam bahan ajar secara bersama-sama dalam satu kelompok. Tiap kelompok membahas materi yang sama, diakhir diskusi kelompok tiap kelompok memaparkan hasil temuan kelompok di depan kelas.

5. Skor kelompok dan penghargaan kelompok Penghargaan ini diberikan dari hasil kerjasama kelompok saat memecahkan masalah yang didiskusikan serta pemaparan hasil diskusi kelompok.

6. Pengajaran materi-materi pokok oleh guru temuan-temuan hasil diskusi kelompok dipertegas oleh guru dengan menerangkan ulang materi-materi yang tidak ditemukan siswa tiap kelompok.

7. Tes formatif

Guru memberikan tes-tes kecil berdasarkan fakta yang diperoleh siswa, misalnya dengan memberikan tugas. 


\section{Metodologi Penelitian}

Jenis penelitian ini adalah penelitian Quasi Eksperimental dengan Desain yang digunakan dalam penelitian ini adalah non-equivalent Posttest-Only Control Group Design. Populasi dalam penelitian ini adalah seluruh siswa kelas XI SMK WIDYA 2 Batam. Adapun sampel dalam penelitian ini adalah kedua kelas XI, dengan teknik pengambilan sampel yaitu sampling jenuh. Sampel dalam penelitian ini berjumlah 34 siswa, yaitu terdiri atas 20 siswa kelas eksperimen dan 14 siswa kelas kontrol. Pada kelas eksperimen diajarkan dengan menggunakan model pembelajaran Team Assisted Individualzation dan kelas kontrol diajarkan dengan menggunakan model pembelajaran konvensional.

Instrumen yang digunakan dalam penelitian ini adalah instrumen tes berupa esai yang telah di uji melalui uji validitas menggunakan validitas konstruk instrumen menggunakan rumus korelasi product moment Person, reliabilitas dengan rumus Alfa Cronbanch, daya pembeda, dan tingkat kesukaran. Teknik analisis data pada normalitas menggunakan teknik Kolmogorov-Smirnov, dan homogenitas. menurut Lestari dan Yudhanegara (Lestari \& Yudhanegara, 2017). Hipotesis 1 dan 2 menggunakan One sampel T-test dan hipotesis 3 menggunakan independent sampel test. (Polled Varians). (Sugiyono, 2011).

\section{Hasil Penelitian dan Pembahasan}

Berdasarkan hasil penelitian yang telah dilaksanakan maka didapatkan nilai pada kedua kelas yang dituliskan pada Tabel 2.

Tabel 2. Data Nilai Hasil Belajar post-test Team Assisted Individualzation

\begin{tabular}{lcc}
\hline $\begin{array}{c}\text { Nilai Hasil Belajar Team Assisted } \\
\text { Individualzation }\end{array}$ & Post-test Eksperimen & Post-test Kontrol \\
\hline N Statistik & 20 & 14 \\
Nilai Minimum Statistik & 61 & 52 \\
Nilai Maksimum Statistik & 99 & 84 \\
Mean Statistik & 81,55 & 71,79 \\
Std. Deviation Statistik & 11,133 & 12,205 \\
Varians Statistik & 123,945 & 148,951 \\
\hline
\end{tabular}

Berdasarkan Tabel 2 di atas dapat diketahui bahwa nilai rata-rata kelas ekperimen lebih tinggi dari pada nilai rata-rata kelas Kontrol. Uji prasyarat analisis menggunakan uji normalitas yaitu Kolmogorov-Smirnov. Berdasarkan perhitungan didapatkan hasil perhitungan dapat dilihat pada tabel 3 sebagai berikut

Tabel 3. Perhitungan Normalitas Kelas Eksperimen

\begin{tabular}{lccc}
\hline \multicolumn{3}{c}{ Kolmogorov Smirnov $^{\text {a }}$} \\
\hline Eksperimen & Statistic & df & Sig. \\
Kontrol & 0,122 & 20 & $0,200^{*}$ \\
\hline
\end{tabular}


Tabel 4. Hasil Perhitungan Homogenitas

\begin{tabular}{cccc}
\hline Levene Statistic & df1 & df2 & Sig. \\
\hline 0,270 & 1 & 32 & 0,607 \\
\hline
\end{tabular}

Berdasarkan perhitungan uji normalitas, diperoleh nilai signifikansi kelas eksperimen yaitu $\alpha=0,200$, maka $0,05<0,200$ dan Kontrol memiliki $\alpha=0,018$, maka $0,05<0,018$ artinya data berdistribusi normal. Dan pada uji homogenitas pada kolom sig. memiliki $\alpha=$ 0,607, maka $0,05<0,607$ artinya data memiliki varian sama atau homogen.

Tabel 5. Hasil Perhitungan data dengan one sample t test

\begin{tabular}{ccccc}
\hline & \multicolumn{5}{c}{ Test Value $=\mathbf{7 0}$} \\
\hline Eksperimen & $\mathrm{t}$ & $\mathrm{df}$ & Sig. (2-tailed) & Mean Difference \\
Kontrol & 4,640 & 19 & 0,000 & 11,550 \\
& 0,547 & 13 & 0,583 & 1,786 \\
\hline
\end{tabular}

Berdasarkan output uji hipotesis eksperimen maka didapat $t_{\text {hitung }}=4,640$ dan $t_{\text {tabel }}=$ 2,093 karena $t_{\text {hitung }}>t_{\text {tabel }}(4,640>2,093)$ maka terdapat pengaruh model pembelajaran kooperatif tipe Team Assisted Individualzation terhadap hasil belajar siswa kelas XI SMK Widya 2 batam. Dan dari output uji hipotesis kontrolMaka didapat $t_{\text {hitung }}=0,547$ dan $t_{\text {tabel }}=$ 2,160 karena $t_{\text {hitung }}<t_{\text {tabel }}(0,547<2,160)$ maka tidak terdapat pengaruh model pembelajaran konvensional terhadap hasil belajar siswa kelas XI SMK Widya 2 batam.

Tabel 6. Hasil Perhitungan data dengan Independens Sample t-test

\begin{tabular}{ccccccc}
\hline \multicolumn{7}{c}{ t-test for Equality of Means } \\
\hline Hasil & $\mathrm{t}$ & $\mathrm{Df}$ & $\begin{array}{c}\text { Sig. } \\
(2 \text {-tailed })\end{array}$ & $\begin{array}{c}\text { Mean } \\
\text { Difference }\end{array}$ & $\begin{array}{c}\text { Std. Error } \\
\text { Difference }\end{array}$ \\
\hline Belajar & $\begin{array}{c}\text { Equal } \\
\text { variances } \\
\text { assumed } \\
\text { Equal }\end{array}$ & 2,420 & 32 & 0,021 & 9,764 & 4,035 \\
& 2,380 & 26,422 & 0,025 & 9,764 & 4,103 \\
& $\begin{array}{c}\text { variances } \\
\text { not assumed }\end{array}$ & & & & & \\
\hline
\end{tabular}

Berdasarkan tabel 6 di atas, hasil pengujian independent sample T-test diketahui bahwa nilai $t_{\text {hitung }}=2,420$. Dengan demikian $t_{\text {hitung }}=2,420>t_{\text {tabel }}=2,037$ hal ini berarti terdapat perbedaan pengaruh antara model pembelajaran kooperatif tipe Team Assisted Individualzation dengan model pembelajaran konvensional terhadap hasil belajar Matematika Kelas XI SMK Widya 2 Batam. 
Pada Kelas eksperimen dengan model tipe Team Assisted Individualzation, pada pertemuan pertama, saat pembagian kelompok kondisi kelas belum dapat terkontrol sepenuhnya. Banyak siswa yang main-main dan mengobrol dengan teman sebangku saat pembentukan kelompok berlangsung. Sebagian siswa sulit diatur dan menimbulkan keributan di dalam kelas. Namun pada pertemuan kedua kondisi sudah mulai terkendali dikarenakan pada pertemuan sebelumnya guru menginformasikan agar siswa sudah duduk dengan kelompoknya masing-masing sebelum dimulainya pembelajaran. Setiap kelompok mendapatkan LKS untuk dikerjakan bersama kelompok.Pada pertemuan ketiga siswa mulia berani untuk maju kedepan kelas dan menjelaskan kerja kelompoknya dan hampir semua kelompok bisa menjwab pertanyaan dalam LKS.Pada pertemuan keempat dan kelima siswa sudah mulai terkendali dan aktif selam pembelajaran berlangsung. Penerapan pembelajaran dengan model kooperatif tipe Team Assisted Individualzation berpengaruh terhadap hasil belajar siswa karena pada pemberian dan pengerjaan soal yang diberikan, Mengerjakan bersama kelompoknya sehingga jika mengalami kesulitan bisa bertanya dengan teman sekelompoknya,

Pada kelas kontrol dengan model pembelajaran konvensional. Pada hari pertama guru terlebih dahulu menyampaikan tujuan pembelajaran dilanjutkan dengan penyampain materi oleh guru dan siswa memperhatikan, pada saat guru menjelaskan materi masih banyak siswa yang masih mengobrol dengan teman sebangku dan kurang beraninya siswa untuk bertanya kepada guru materi yang kurang dipahaminya. Saat pemberikan LKS siswa masih banyak yang bertanya kepada teman dan saat di pilih untuk maju siswa malu-malu dan tidak percaya diri untuk menjelaskan kepada teman-teman sekelas dan saat guru memberikan tugas rumah masih banyak siswa yang masih menyontek hingga semua jawaban sama, upaya yang diberikan oleh guru adalah saat pertemuan selanjutnya memilih siswa untuk maju kedepan kelas dan menjelaskan apa yang telah dibuatnya. Pada pertemuan kedua dan ketiga siswa mulai mengerjakan LKS tampa bertanya kepada temananya dan pada guru meanggil untuk menjelaskan ke depan siswa mulai berani menjelaskan hasil kerjanya kepada teman sekelas tetapi jawaban siswa masih ada yang kurang tepat. Pada pertemuan ketiga hingga kelima siswa mulai memahami materi, mengerjakan LKS sendiri-sendiri dan saat maju kedepan untuk mempresentasikan siswa hampir menyelesaikan soal dengan benar dan tidak ragu-ragu.

Hal ini juga sejalan dengan penelitian menurut Huda (Huda, 2014) menunjukkan adanya keunggulan dari model pembelajaran TAI yaitu bahwa siswa yang saling membantu proses belajarnya satu sama lain yang akan berpengaruh signifikan terhadap akademik mereka. Dimana dalam menggunakan model pembelajaran Team Assisted Individualzation memudahkan siswa dalam menyelesaikan persoalan dan pada saat presentasi tidak hanya teman yang bisa tetapi teman yang tidak bisa juga diberikan kesempatan sehingga membuat siswa termotivasi untuk meningkatkan hasil belajar

\section{Kesimpulan}

Dari hasil penelitian yang telah dilakukan dan pembahasannya pada bab sebelumnya maka peneliti dapat menarik beberapa kesimpulan, yaitu:

1. Terdapat pengaruh model pembelajaran kooperatif tipe Team Assisted Individualzation terhadap hasil belajar siswa kelas XI SMK Widya 2 batam. 
2. Tidakterdapat pengaruh model pembelajaran konvensional terhadap hasil belajar siswa kelas XI SMK Widya 2 batam.

3. Terdapat perbedaan pengaruh antara model pembelajaran kooperatif tipe Team Assisted Individualzation denganmodel pembelajaran konvensionalterhadap hasil belajar Matematika Kelas XI SMK Widya 2 Batam.

\section{Daftar Pustaka}

Huda, M. (2014). Cooperatif Learning Metode Teknik Struktur dan Model Penerapan. Yogyakarta: Pustaka Belajar.

Istarani \& Ridwan, M. (2014). Tipe Pembelajaran Kooperatif. Medan: CV Media Persada.

Lestari, K. E., \& Yudhanegara, M. (2017). Penelitian Pendidikan Matematika. Bandung: Refika Aditama.

Shoimin, A. (2014). Model Pembelajaran Inovatif dalam Kurikulum 2013. Yogyakarta: ArRuzz Media.

Sugiyono. (2011). Statistika untuk Penelitian. Bandung: Alfabeta. 